\title{
The Hot Deformation Activation Energy of 7050 Aluminum Alloy under Three Different Deformation Modes
}

\author{
Deli Sang ${ }^{1,2}$, Ruidong Fu ${ }^{1,2, *}$ and Yijun $\mathrm{Li}^{1,2}$ \\ 1 State Key Laboratory of Metastable Materials Science and Technology, Yanshan University, \\ Qinhuangdao 066004, China; S13930385984@126.com (D.L.S.); liyijun1987@126.com (Y.J.L.) \\ 2 College of Materials Science and Engineering, Yanshan University, Qinhuangdao 066004, China \\ * Correspondence: rdfu@ysu.edu.cn; Tel.: +86-335-807-4792; Fax: +86-335-807-4545 \\ Academic Editor: Nong Gao \\ Received: 21 January 2016; Accepted: 23 February 2016; Published: 29 February 2016
}

\begin{abstract}
In this study, the hot deformation activation energy values of 7050-T7451 aluminum alloy, calculated with two different methods under three deformation modes, were compared. The results showed that the hot deformation activation energy values obtained with the classical constitutive equation are nearly equivalent under the hot tensile, compression, and shear-compression deformation modes. Average values exhibited an obvious increase when calculated with the modified constitutive equation because it can reflect the variation of activation energy with deformation conditions such as deformation temperature, strain rate and strain state. Moreover, the values under tensile and compression deformation modes were nearly the same regardless of the calculation method. The higher average value under the shear-compression deformation mode with modified equation indicates that the strain state has a significant effect on the hot deformation activation energy. In addition, when the activation energy was investigated for various deformation conditions, the effect of the strain state on the activation energy was more significant. Under a certain condition, the activation energy was the same for the three deformation modes.
\end{abstract}

Keywords: activation energy; hot deformation; aluminum alloy; deformation mode

\section{Introduction}

Actual production processes of metals and alloys are always accompanied by various hot deformation processes such as forging, rolling, extrusion, and welding. Therefore, the hot deformation behavior of metals and alloys has been an important scientific issue. As an indication of the degree of difficulty during hot deformation processes, hot deformation activation energy is typically used to estimate the hot workability and to optimize the hot working process of metals and alloys [1-3]. For example, a typical application of activation energy is that it is used to derive the constitutive equation, which generally consists of the response of flow stress, strain rate, and deformation temperature. Among the various constitutive models and equations available, the hyperbolic sine law proposed by Sellars and McTegart [4] is the most applicable for a wide range of stresses and has been extensively used to study the hot deformation behavior of various metals and alloys. Moreover, activation energy is always treated as a constant in the constitutive equation regardless of the applied hot deformation conditions such as temperature, strain rate, and load state.

However, the hot deformation activation energy is correlated with not only material composition and heat treatment conditions but also deformation conditions and deformation mode. For instance, Reyes-Calderón et al. [5] found that the presence of microalloying elements such as $\mathrm{Nb}, \mathrm{V}$, and $\mathrm{Ti}$ increased the activation energy of the nonmicroalloyed material from $366 \mathrm{~kJ} \cdot \mathrm{mol}^{-1}$ to $446 \mathrm{~kJ} \cdot \mathrm{mol}^{-1}$ of 
V-microalloyed twinning induced plasticity steel. For aluminum alloys, the hot deformation activation energy is affected significantly by the initial state of the material because the solute atoms diffuse to the dislocation cores and are pinned at the dislocations [6-9]. Recently, Zhang et al. [10] found that the hot deformation activation energy of Ti-15-3 titanium alloy increases with increasing temperature and decreasing strain rate. Shi et al. [11] found that the hot deformation activation energy of an AA7150 aluminum alloy is not constant and decreases with increasing deformation temperature and strain rate. Therefore, a modified constitutive equation was proposed, wherein the term for activation energy is treated as a variant involving temperature and strain rate.

Recently, considerable work has been performed on the strain state effects. Although the research has primarily focused on aluminum alloys under cold working conditions, variations in strain state have a significant effect on the deformation microstructure, particularly the development of dislocation structures [12,13]. Therefore, as a reflection of the energy barrier to dislocation motion for metals and alloys during hot deformation, the hot deformation activation energy may be affected by the deformation modes for different strain states. However, it has not yet been verified.

In this paper, hot tensile (HT), hot compression (HC), and hot shear-compression (HSC) tests of a 7050-T7451 aluminum alloy have been performed at different temperatures and strain rates. The hot deformation activation energy under these three deformation modes was calculated using the classical constitutive equation and the modified equation. The effect of deformation conditions, modes, and calculation methods on activation energy was discussed.

\section{Material and Methods}

The chemical composition (wt. \%) of the investigated 7050-T7451 aluminum alloy is shown in Table 1. The alloy was obtained in an as-rolled plate with a gauge thickness of $22 \mathrm{~mm}$. The hot deformation specimens were prepared by using wire-electrode cutting. The HT and HC specimens are $100 \mathrm{~mm}$ and $12 \mathrm{~mm}$ in length and $6 \mathrm{~mm}$ and $8 \mathrm{~mm}$ in diameter, respectively. The HSC test is same to the classical HC test. However, because of the special design of the HSC specimen [14] schematically presented in Figure 1, that shear and compression strain are induced simultaneously by axial force in the specimen. The three hot deformation tests were performed on a Gleeble 3500 thermo-mechanical simulator (Dynamic Systems Inc. (DSI), Poestenkill, NY, USA) at axial strain rates and deformation temperatures ranging from $0.01 \mathrm{~s}^{-1}$ to $10 \mathrm{~s}^{-1}$ and from $523 \mathrm{~K}$ to $723 \mathrm{~K}$, respectively. During the tests, all the specimens were heated to the selected deformation temperature at a heating rate of $20 \mathrm{~K} \cdot \mathrm{s}^{-1}$ and held at the deformation temperature for $30 \mathrm{~s}$ prior to deformation. The thermal cycle with no solution treatment and short dwell time is on account of modeling the process such as friction welding process [15]. The HT, HC, and HSC specimens were deformed to snap break, height reductions of $50 \%$, and a total axial displacement of $4.5 \mathrm{~mm}$, respectively. Thereafter, all the specimens were immediately water quenched.

Table 1. Chemical composition (wt. \%) of the 7050 aluminum alloy.

\begin{tabular}{cccccccccc}
\hline \multicolumn{10}{c}{ Chemical Composition (wt. \%) } \\
\hline $\mathrm{Si}$ & $\mathrm{Fe}$ & $\mathrm{Cu}$ & $\mathrm{Mn}$ & $\mathrm{Mg}$ & $\mathrm{Cr}$ & $\mathrm{Zn}$ & $\mathrm{Ti}$ & $\mathrm{Zr}$ & $\mathrm{Al}$ \\
0.12 & 0.15 & $2.0 \sim 2.6$ & 0.1 & $1.9 \sim 2.6$ & 0.04 & $5.7 \sim 6.7$ & 0.06 & $0.08 \sim 0.15$ & Bal. \\
\hline
\end{tabular}




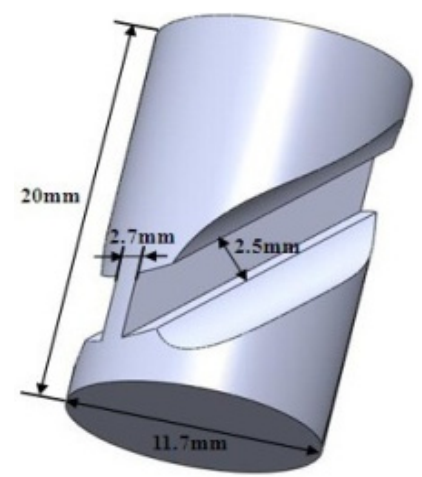

Figure 1. Schematic presentation of the shear-compression specimen.

\section{Results}

\subsection{Flow Stress during the Three Hot Deformation Processes}

The flow stress vs. strain curves during the three hot deformation processes are shown in Figure 2. As can be seen, in all the cases, the flow stress increases rapidly in the initial stage of deformation then either decreases to a certain degree or remains constant after the peak stress. Moreover, the flow stress increases with an increase in strain rate and decrease in deformation temperature. Flow stress is a function of dislocation density [16]. During the hot deformation process, the dislocation density is affected by the primary microstructure, temperature, and strain rate. If these parameters are constant, the variation of flow stress is related to the microstructure evolution. Before the peak stress is reached, the dislocations multiply drastically, and the work hardening process prevails over the softening process. Therefore, the flow stress increases rapidly. After the initial deformation stage, the work hardening and softening processes induced by dynamic recovery (DRV) and dynamic recrystallization (DRX) compete. Moreover, the flow stress still increases, but the rate of increase decreases continuously. After the peak value, the softening process becomes dominant. Initially, the peak stresses were determined from the flowing stress vs. strain curves under different deformation conditions and were used to calculate the activation energy. The choice is on account of two aspects: In aluminum alloys, the peak stress is generally used and refers to a dynamic equilibrium between the work hardening and dynamic softening processes [17,18]. All the deformation processes can be assumed to be homogeneous up to the peak stress excluding the effects of strain state induced by bulging or necking.
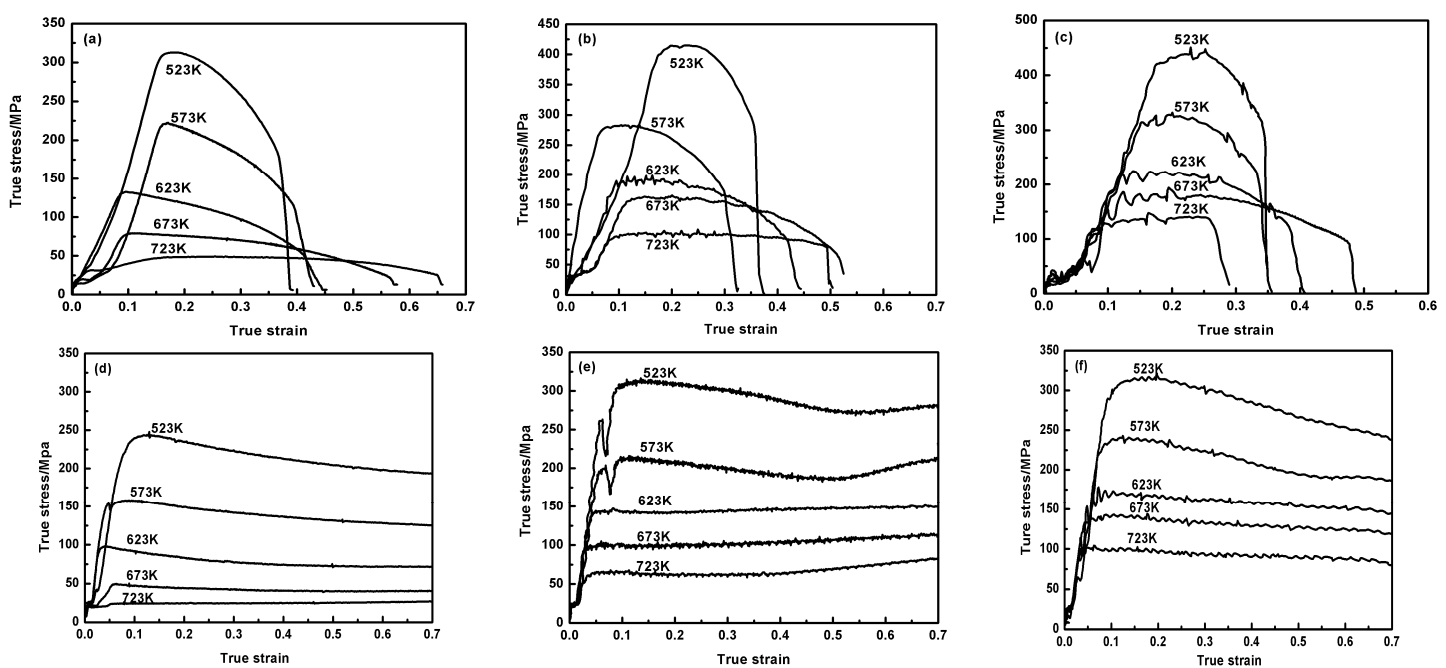

Figure 2. Cont. 

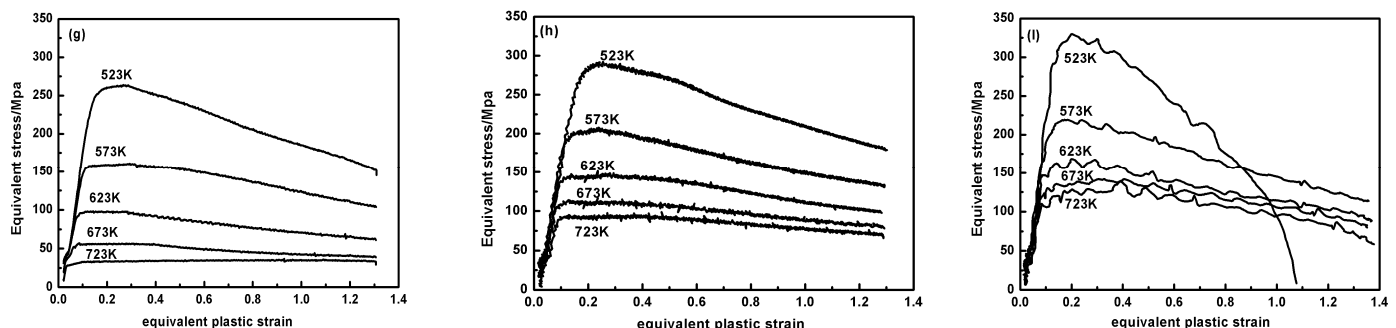

Figure 2. Flow stress $v$ s. strain curves for 7050 aluminum alloy at hot tensile (HT) mode: (a) $0.01 \mathrm{~s}^{-1}$; (b) $1 \mathrm{~s}^{-1}$; (c) $10 \mathrm{~s}^{-1}$; HC mode: (d) $0.01 \mathrm{~s}^{-1}$; (e) $1 \mathrm{~s}^{-1}$; (f) $10 \mathrm{~s}^{-1}$; and HCS mode: (g) $0.01 \mathrm{~s}^{-1}$; (h) $1 \mathrm{~s}^{-1}$; (i) $10 \mathrm{~s}^{-1}$.

\subsection{Calculation of the Hot Deformation Activation Energy}

The hot deformation activation energy parameter provides important information about the deformation mechanism associated with microstructural evolution, especially the dislocation movement, DRV, DRX, and the movement of grain boundaries. If the activation energy is treated as a constant, according to the process of established classical constitutive relations, we can calculate the activation energy using the hyperbolic sine constitutive law [4]:

$$
\dot{\varepsilon}=A[\sinh (\alpha \sigma)]^{n} \exp (-Q / R T)
$$

where $\alpha, n$ and $A$ are material constants, and $R$ is the universal gas constant $\left(8.314 \mathrm{~J} \cdot \mathrm{mol}^{-1} \cdot \mathrm{K}\right) ; T$ is the deformation temperature $(\mathrm{K})$; and $Q$ is the hot deformation activation energy $\left(\mathrm{kJ} \cdot \mathrm{mol}^{-1}\right)$. Moreover, $\sigma$ can either be the peak stress or steady flow stress (MPa). In this study, the peak stress $\sigma_{\mathrm{p}}$ was used.

We obtained approximately equal values of activation energy with the classical equation $\left(Q_{1}\right.$ shown in Table 2) under the three hot deformation modes. In the classical constitutive equation, $n$ and $A$ are regarded as material constants, and it defines $\alpha$ as $\alpha=\beta / n_{1}$ [4], where $\beta$ and $n_{1}$ are the slopes of the plots of $\ln \dot{\varepsilon}-\sigma_{\mathrm{p}}$ and $\ln \dot{\varepsilon}-\ln \left(\sigma_{\mathrm{p}}\right)$, respectively. Furthermore, the constitutive equation involves the assumption that during the hot deformation process, any microstructure transformation mechanism is absent [17]. In addition, the material components and heat treatment conditions are identical. Consequently, the activation energy may be assumed to be a constant independent of the deformation conditions and modes on the basis of the approximately equal values. On the other hand, the activation energy $\left(Q_{1}\right)$ calculated with Equation (1) can be comprehended to be, in fact, an average value.

Table 2. Values of material constants and activation energy $Q_{1}$ for the 7050 aluminum alloy.

\begin{tabular}{cccccc}
\hline Deformation Mode & $\boldsymbol{A}$ & $\alpha=\beta / \mathbf{n}_{\mathbf{1}} \mathbf{( \mathbf { M P a } ^ { - 1 } )}$ & $\boldsymbol{n}$ & $\boldsymbol{S}$ & $\boldsymbol{Q}_{\mathbf{1}} \mathbf{( \mathbf { k J } \cdot \mathbf { ~ m o l } ^ { - 1 } )}$ \\
\hline HT & $1.27 \times 10^{20}$ & 0.0051 & 8.05 & 3.62 & 241.38 \\
HC & $2.31 \times 10^{19}$ & 0.0066 & 7.34 & 3.88 & 236.69 \\
HSC & $1.67 \times 10^{20}$ & 0.0054 & 8.59 & 3.36 & 239.93 \\
\hline
\end{tabular}

However, ensuring the microstructure constant during hot deformation is difficult because the microstructures involve various complex interactions among the dislocations, solutes or precipitates, grain boundaries, or periodic friction of the lattice. These processes are strongly affected by strain, strain rate, and deformation temperature. Therefore, the hot deformation activation energy will vary with these deformation conditions. From Equation (2), in which the activation energy is temperature and strain rate dependent [11], the activation energy, $Q_{2 v}$, under different deformation conditions were 
calculated. The results are listed in Table 3. As can be seen, $Q_{2 v}$ decreases with an increase in strain rate and temperature, and the deformation modes significantly affect it.

$$
\dot{\varepsilon}=A(T, \dot{\varepsilon})[\sinh (\alpha \sigma \mathrm{p})]^{n(T)} \exp \left(-\frac{Q(T, \dot{\varepsilon})}{R T}\right)
$$

Table 3. Values of activation energy $Q_{2 v}$ for the 7050 aluminum alloy under three deformation modes.

\begin{tabular}{cccccccccc}
\hline & \multicolumn{9}{c}{ Strain Rate $\left(\mathbf{s}^{-1}\right)$} \\
\cline { 2 - 11 } $\begin{array}{c}\text { Deformation } \\
\text { Temperature (K) }\end{array}$ & \multicolumn{3}{c}{ HT } & \multicolumn{9}{c}{ HC } & & \multicolumn{3}{c}{ HSC } \\
\cline { 2 - 11 } & $\mathbf{0 . 0 1}$ & $\mathbf{1}$ & $\mathbf{1 0}$ & $\mathbf{0 . 0 1}$ & $\mathbf{1}$ & $\mathbf{1 0}$ & $\mathbf{0 . 0 1}$ & $\mathbf{1}$ & $\mathbf{1 0}$ \\
\hline 523 & 391.3 & 323.0 & 304.5 & 517.5 & 379.4 & 326.0 & 654.9 & 398.6 & 374.3 \\
573 & 349.4 & 288.3 & 271.8 & 429.0 & 314.7 & 270.0 & 597.2 & 385.7 & 341.3 \\
623 & 307.4 & 253.5 & 239.0 & 340.5 & 250.0 & 214.0 & 398.4 & 242.5 & 227.7 \\
673 & 265.5 & 218.8 & 206.3 & 252.0 & 185.3 & 158.1 & 251.7 & 153.2 & 143.8 \\
723 & 223.6 & 184.0 & 173.5 & 163.5 & 120.6 & 102.1 & 176.8 & 107.6 & 101.1 \\
\hline Average $\left(Q_{2}\right)$ & & 266.7 & & & 268.2 & & & 314.3 & \\
\hline
\end{tabular}

\section{Discussion}

Generally, the hot deformation activation energy can qualitatively reflect the energy barrier to dislocation motion for metals and alloys during hot deformation. A higher value of activation energy signifies the existence of higher dragging forces to the movement of the dislocation in hot deformation. The activation energy $Q_{1}$ under the three deformation modes are greater than those for the homogenized and aged 7xxx aluminum alloys [7-9]. This deviation is mainly due to the difference in the microstructure state of the alloy in experiments that the specimens were heated rapidly to the testing temperature and held for $30 \mathrm{~s}$ before loading. In such a short dwell time, the precipitates may not be completely dissolved and the dragging forces to the movement of the dislocation still exist in the subsequent deformation. Therefore, the activation energy exhibits a higher value.

A comparison of $Q_{1}$ and $Q_{2}$ values for the three deformation modes is shown in Figure 3. The values of $Q_{1}$, which can be considered as the average values under the different deformation conditions, are approximately equal under the three deformation modes. Moreover, the deformation modes do not affect the thermal activation processes, which lead to confusion in the current understanding the nature of hot deformation activation energy. In comparison, an obvious increase can be found in $Q_{2}$ values for the three deformation modes. Moreover, $Q_{2}$ of the HT mode is nearly identical to the value of the HC mode, but is lower than the value of the HSC mode (see in Table 3). Notably, the values of the activation energies $Q_{1}$ and $Q_{2}$ are approximate equivalent under both the HT and HC modes irrespective of the calculation method employed. This behavior can be attributed to the similar loading path for the HT and HC deformation modes when the stress reaches the peak value. Tensile or compressive loading can activate a larger number of slip systems when compared with torsion or shear loading [12]. In HT and HC deformations, a large number of slip systems are activated. Nevertheless, the increase in activation energy $Q_{2}$ resulting from the calculated methods should be paid more attention, particularly to the significant increase of activation energy $Q_{2}$ under the HSC deformation mode. When compared with HT and HC deformations, relatively fewer slip systems can be activated with the complex strain state in the slot position of the HSC specimen. Complicated interactions of different slip systems and intricate dislocation structures induce a much higher obstruction resulting in the higher activation energy in HSC. These results indicate that the modified equation is more suitable to calculate the activation energy for the hot deformation under a complex strain state. Moreover, the hot deformation activation energy is affected by deformation conditions as well as the strain state. 


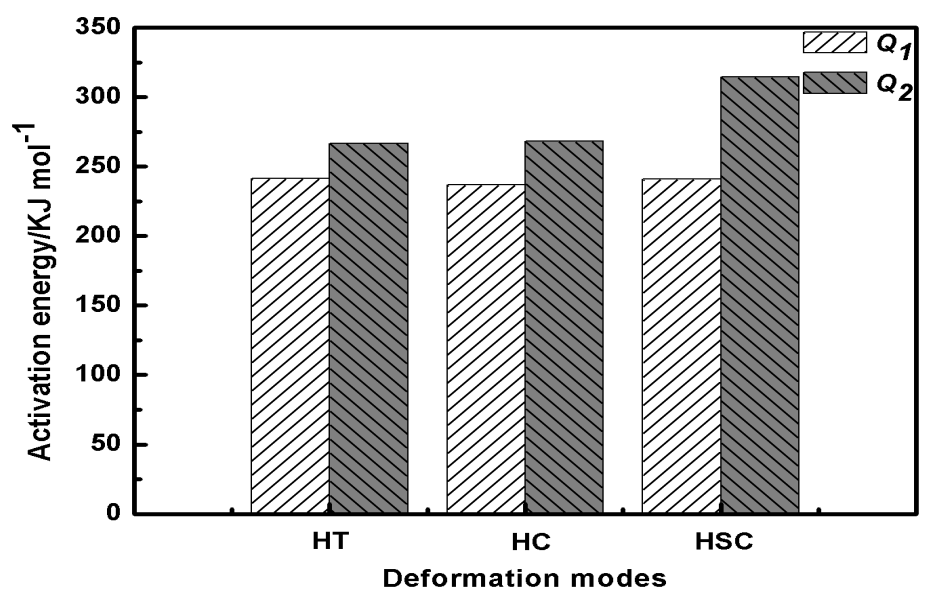

Figure 3. Comparison between the average values of the activation energy $Q_{1}$ and $Q_{2}$ for the three deformation modes.

The effect of the strain state on the activation energy can be seen in Figure 4. It shows the variation of the activation energy $Q_{2 v}$ as a function of temperature for the three deformation modes. As can be seen, $Q_{2 v}$ is not constant but decreases with increasing temperature. Furthermore, the relationship is perfectly linear under HT and HC deformations. This phenomenon may be attributed to the thermodynamic mechanism of dislocation movement, which is a thermally activated process [19]. It is related to the critically resolved shear stress [20]. When the temperature increases, rearrangement and annihilation of dislocations occur to improve DRV, which reduces the resistance of dislocation motion and leads to a reduced activation energy. Specifically, the variation under HSC deformation is similar to that under the other modes, but the relationship is not linear. This difference is due to the complex strain state and increased external shear stress induced by HSC deformation.
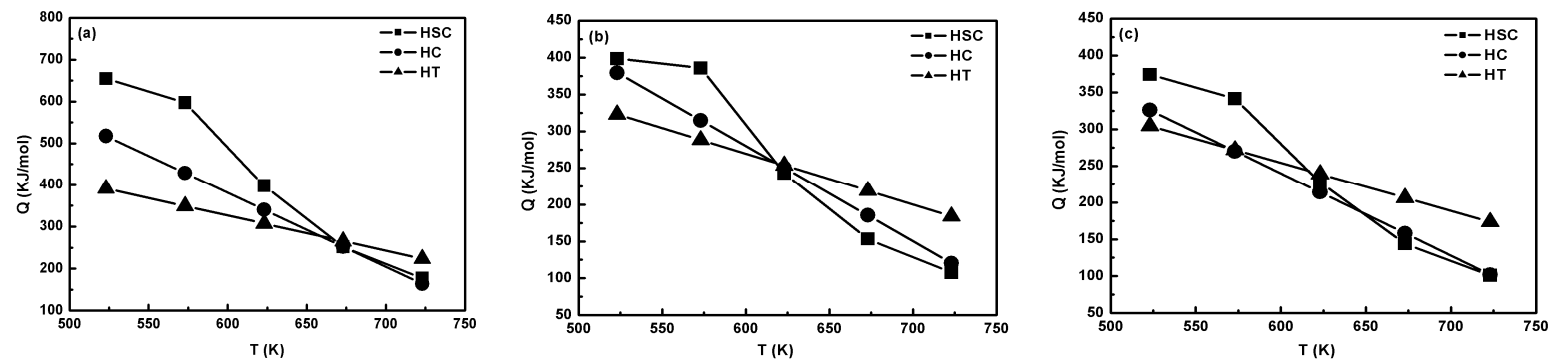

Figure 4. Relationship of hot deformation activation energy $v s$. deformation temperature for 7050 aluminum alloy under three deformation modes: (a) $0.01 \mathrm{~s}^{-1}$; (b) $1 \mathrm{~s}^{-1}$; (c) $10 \mathrm{~s}^{-1}$.

An interesting phenomenon in Figure 4 is the intersection of the curves, which indicates that the activation energy $Q_{2 v}$ is approximately same at some deformation conditions for these deformation modes. In addition, the intersection varies with increasing strain rate and decreasing temperature, which may be due to precipitates, dislocation patterns, stress state, or other factors affecting the development of dynamic microstructure. However, the exact cause of the phenomenon is unclear and must be studied in the future.

\section{Conclusions}

1. By comparing the hot deformation activation energy values calculated using the classical and modified equations, the modified equation is found to be more suitable to calculate the hot deformation activation energy under the complex strain state. 
2. With the modified constitutive equation, the hot deformation activation energy is greater under the HSC deformation mode than under the HT and HC deformation modes. It is attributed to the fewer and different slip systems and intricate dislocation structures promoted in HSC deformation. Therefore, the significantly higher obstruction induced by their complicated interactions results in the higher activation energy in HSC deformation case.

3. The effect of the strain state on the hot deformation activation energy can also be seen from the variation of the activation energy with the deformation conditions under the three deformation modes. It indicates that the complex strain state facilitates the increase activation energy under the same deformation conditions.

Acknowledgments: The authors thank the China Friction Stir Welding Center, Beijing Friction Stir Welding Technology Limited Company for financial support.

Author Contributions: Deli Sang performed research, analyzed the data and wrote the paper; Yijun Li helped in the experimental part; Ruidong Fu assisted in the data analysis and revised manuscript.

Conflicts of Interest: The authors declare no conflict of interest.

\section{Abbreviations}

$\begin{array}{ll}\text { HT } & \text { Hot Tensile } \\ \text { HC } & \text { Hot Compression } \\ \text { HSC } & \text { Hot Shear-Compression } \\ \text { DRV } & \text { Dynamic Recovery } \\ \text { DRX } & \text { Dynamic Recrystallization }\end{array}$

\section{References}

1. Deschamps, A.; Brechet, $\mathrm{Y}$. Influence of quench and heating rates on the ageing response of an $\mathrm{Al}-\mathrm{Zn}-\mathrm{Mg}$-(Zr) alloy. Mater. Sci. Eng. A 1998, 251, 200-207. [CrossRef]

2. McQueen, H.J.; Spigarelli, S.; Kassner, M.; Evangelista, E. Hot Deformation and Processing of Aluminum Alloys; CRC Press: Boca Raton, FL, USA, 2011.

3. Zhang, M.J.; Li, F.G.; Wang, S.Y.; Liu, C.Y. Characterization of hot deformation behavior of a P/M nickel-base superalloy using processing map and activation energy. Mater. Sci. Eng. A 2010, 527, 6771-6779.

4. Sellars, C.M.; McTegart, W.J. On the mechanism of hot deformation. Mem. Sci. Rev. Met. 1966, 63, 731-746. [CrossRef]

5. Reyes-Calderón, F.; Mejía, I.; Cabrera, J.M. Hot deformation activation energy (QHW) of austenitic Fe-22Mn-1.5Al-1.5Si-0.4C TWIP steels microalloyed with Nb, V, and Ti. Mater. Sci. Eng. A 2013, 562, 46-52. [CrossRef]

6. Rokni, M.R.; Zarei-Hanzaki, A.; Roostaei, A.A.; Abolhasani, A. Constitutive base analysis of a 7075 aluminum alloy during hot compression testing. Mater. Des. 2011, 32, 4955-4960. [CrossRef]

7. Jin, N.P.; Zhang, H.; Han, Y.; Wu, W.; Chen, J. Hot deformation behavior of 7150 aluminum alloy during compression at elevated temperature. Mater. Charact. 2009, 60, 530-536. [CrossRef]

8. Sheppard, T.; Jackson, A. Constitutive equations for use in prediction of flow stress during extrusion of aluminum alloys. Mater. Sci. Technol. 1997, 13, 203-209. [CrossRef]

9. Cerri, E.; Evangelista, E. Comparative hot workability of 7012 and 7075 alloys after different pretreatments. Mater. Sci. Eng. A 1995, 197, 181-198. [CrossRef]

10. Zhang, J.Q.; Di, H.S.; Wang, H.T.; Mao, K.; Ma, T.J.; Cao, Y. Hot deformation behavior of Ti-15-3 titanium alloy: A study using processing maps, activation energy map, and Zener-Hollomon parameter map. J. Mater. Sci. 2012, 47, 4000-4011. [CrossRef]

11. Shi, C.J.; Mao, W.M.; Chen, X.-G. Evolution of activation energy during hot deformation of AA7150 aluminum alloy. Mater. Sci. Eng. A 2013, 571, 83-91. [CrossRef]

12. Miller, M.P.; McDowell, D.L. Modeling large strain multiaxial effects in FCC polycrystals. Int. J. Plast. 1996, 12, 875-902. [CrossRef] 
13. Davenport, S.B.; Higginson, R.L. Strain path effects under hot working: An introduction. Mater. Pro. Technol. 2000, 98, 267-291. [CrossRef]

14. Rittel, D.; Lee, S.; Ravichandran, G. A shear-compression specimen for large strain testing. Exper. Mech. 2002, 42, 58-64. [CrossRef]

15. Masaki, K.; Sato, Y.S.; Maeda, M.; Kokawa, H. Experimental simulation of recrystallized microstructure in friction stir welded Al alloy using a plane-strain compression test. Scr. Mater. 2008, 58, 355-360. [CrossRef]

16. Dieter, G.E. Mechanical Metallurgy, 3rd ed.; McGraw-Hill: New York, NY, USA, 1987.

17. McQueen, H.J.; Ryan, N.D. Constitutive analysis in hot working. Mater. Sci. Eng. A 2002, 322, 43-63. [CrossRef]

18. Medina, S.F.; Hernandez, C.A. General expression of the Zener-Hollomon parameter as a function of the chemical composition of low alloy and microalloyed steels. Acta Metar. 1996, 44, 137-148. [CrossRef]

19. Caillard, D.; Martin, J.L. Thermally Activated Mechanisms in Crystal Plasticity; Pergamon Press: Oxford, UK, 2003.

20. Honeycombe, R.W.K. The Plastic Deformation of Metals, 2nd ed.; Edward Arnold Ltd.: Baltimore, MD, USA, 1984.

(C) 2016 by the authors; licensee MDPI, Basel, Switzerland. This article is an open access article distributed under the terms and conditions of the Creative Commons by Attribution (CC-BY) license (http://creativecommons.org/licenses/by/4.0/). 